Article

\title{
Rheological Issues of Phase Change Materials Obtained by the Complex Coacervation of Butyl Stearate in Poly Methyl Methacrylate Membranes
}

\author{
Vasile Bendic ${ }^{1}$, Dan Dobrotă ${ }^{2, *(\mathbb{D})}$, Tiberiu Dobrescu ${ }^{1}$, George Enciu ${ }^{1}$ and \\ Nicoleta-Elisabeta Pascu ${ }^{3}$ \\ 1 Faculty of Engineering and Management of Technological Systems, Politehnica University of Bucharest, \\ 060042 Bucharest, Romania; vasile.bendic@upb.ro (V.B.); tiberiu.dobrescu@upb.ro (T.D.); \\ george.enciu@upb.ro (G.E.) \\ 2 Faculty of Engineering, Lucian Blaga University of Sibiu, 550024 Sibiu, Romania \\ 3 Faculty of Aerospace Engineering, Politehnica University of Bucharest, 060042 Bucharest, Romania; \\ nicoleta.pascu@upb.ro \\ * Correspondence: dan.dobrota@ulbsibiu.ro; Tel.: +40-0722-446-082
}

Received: 18 February 2019; Accepted: 6 March 2019; Published: 9 March 2019

check for updates

\begin{abstract}
The research started from the fact that the coacervation process represents the process of formation of macromolecular aggregates after separation from the phase that takes place in a homogeneous polymer solution as a result of the addition of a non-solvent. This process is very complex, and takes place in several stages of emulsification technology. The first step of the research created a sample through an encapsulation process of complex coacervation, followed by the creation of three different samples with specific emulsification technologies. Each resulting sample and step of emulsification went through rheological analysis, including the development of evolutions of the complex viscosity, loss module and respective storage module. When we analyzed the rheological properties of each sample at different emulsification stages, we reached the conclusion that, at the moment when the polymerization reaction develops the methyl methacrylate (MMA), the loss modules of the samples were stronger than the storage modules. In this context, the emulsification technology strongly influenced the process of forming the polymethyl methacrylate (PMMA) layer over the butyl stearate particles. In addition, in order to obtain the corresponding microcapsules, it was preferable for the butyl stearate particles covered with MMA to be vigorously stirred in a short period of time, under $250 \mathrm{~s}$, because after that the polymerization process of the MMA on the surface of the particles begins. When producing microcapsules, it is very important that the whole process of emulsification be accompanied by rigorous stirring.
\end{abstract}

Keywords: phase change materials; complex coacervation; rheological properties; butyl stearate; polymethyl methacrylate

\section{Introduction}

Phase change materials (PCM) are increasingly used in thermal energy storage systems and temperature control systems due to the advantages they offer, namely high capacity storage in a reduced volume and the possibility of maintaining a near constant temperature in an enclosure [1-3]. The variables that affect the performance of thermal energy storage systems can be divided into the following categories: variables related to PCMs and storage tank geometry (shape and size of the PCM capsule, length and diameter of the storage tank, capsule geometry and tank geometry storage); variables related to the flow of the transfer fluid (debit, speeds, fluid properties); variables associated 
with the storage system response (initial state, entrance temperature, PCM physical and thermal properties, convection thermal transfer coefficient) [4-8].

The use of PCMs is limited by the relatively low thermal conductivity of these materials, and also by the possibility of leakage occurring during the time the material is in the liquid phase. Micro-encapsulation creates conditions for incorporating PCMs into conventional building materials, and such materials have the advantages of easy application, good heat transfer, and no need of protection against destruction. A possible solution for obtaining a PCM with superior characteristics would be to embed the phase change material into a polymeric mass and close the PCM in a polymeric membrane to create a material which avoids leakage (PCM). The most commonly used methods for the preparation of microcapsules are chemical methods, including in situ polymerization, interfacial polymerization, separation of internal phases and solvent evaporation techniques [9-11].

For the realization of membranes according to previously specified methods, the most commonly used materials in practice are polymethyl methacrylate, melamine-formaldehyde, urea-formaldehyde resin, and polyurea silica. In the very near future, new materials may appear that can be used for micro-encapsulation, namely epoxide, polydimethylsiloxane, glycidyl methacrylate, dry oil, isocyanate and aliphatic amines $[12,13]$.

Obtaining the polymeric membrane can be accomplished by applying various micro and macro-encapsulation techniques such as immersion and direct incorporation. Thus, in order to avoid the occurrence of the leakage of phase change material, it is necessary to create a membrane with a higher melting temperature than the material with phase change, and to add certain compounds that allow the increasing viscosity of the PCM [14-17].

In addition, in order to avoid leakage of the phase change material in the case of paraffin, in practice it is advisable to use polyethylene (PE) as a sealant and to form a membrane around the PCM [17].

A possible solution for obtaining a membrane around a phase change material is coacervation, which is a physico-chemical microencapsulation method. The coacervation process is the process of forming macromolecular aggregates following phase separation that happens in a homogeneous polymer solution through the addition of a non-solvent [18-20]. Depending on how it is formed, the membrane around the phase transformation material can be used for simple coacervation or complex coacervation. If an interaction between the solution of a single polymer and the encapsulated substance is achieved, the process is simple coacervation, and if the coacervation is accomplished by an interaction between two polymers, it is called compound or complex coacervation [21-24]. Currently, the coacervation process of macromolecular compounds is considered the process by which a biphasic system is formed by stratification [25-27].

Thus, the process of microencapsulation by coacervation is very complex, and the research in this paper mainly focused on optimizing the process of obtaining a polymethyl methacrylate membrane that will encapsulate the phase change material, namely butyl stearate.

An analysis of the rheological properties for the various emulsifying steps used to obtain microcapsules of butyl stearate encapsulated in poly methyl methacrylate was performed in this research. Thus, it was possible to establish the optimal conditions for emulsification in order to obtain butyl stearate microcapsules that would not allow liquid phase leakage and would also be energy efficient.

In a first phase, a sample was made by preliminary technology, after which three distinct samples were made with specific emulsification technologies that were subjected to rheological analysis. We established the evolution of the viscosity over time complex, loss module and storage module for each sample and emulsifying step.

\section{Materials and Methods}

The process of obtaining microcapsules of phase change material (PCM) was based on the fundamental principle of encapsulation, namely the coating of a substance (butyl stearate) in a 
membrane of MMA (methyl methacrylate), which is inert. The basis of the process of obtaining the microcapsules was complex coacervation and it was envisaged to mix two solutions of two hydrophilic colloids under suitable conditions. In the complex coacervation process, the action between positive and negative charges of two $\mathrm{pH}$-changing polymers was also considered. Figure 1 presents the steps of the complex coacervation polymerization process used to obtain the butyl stearate microcapsules. In Figure 2 we can see a schematic representation of the polymerization process through complex coacervation for obtaining the PCM.

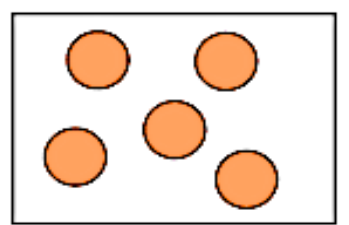

a

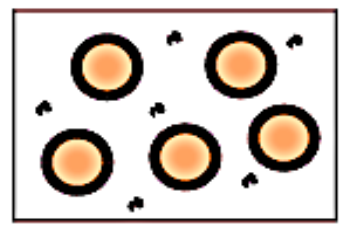

d

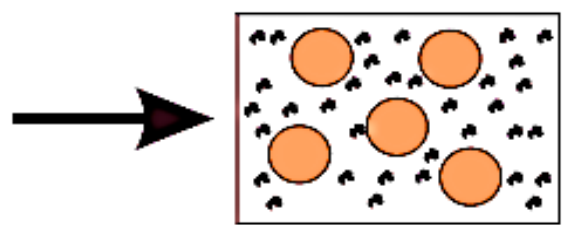

$1^{b}$

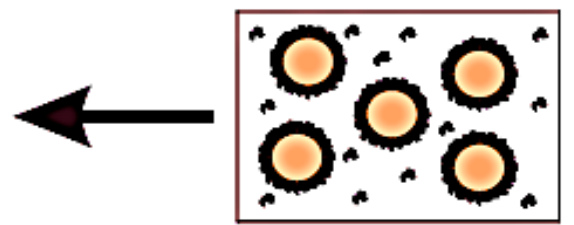

C

Figure 1. Stages of the complex coacervation polymerization process. (a) emulsifying PCM core material in water; (b) addition of MMA and ally-MMA monomers; (c) coating the core material with monomeric microparticles; (d) adding the initiator and capsule formation by polymerization.

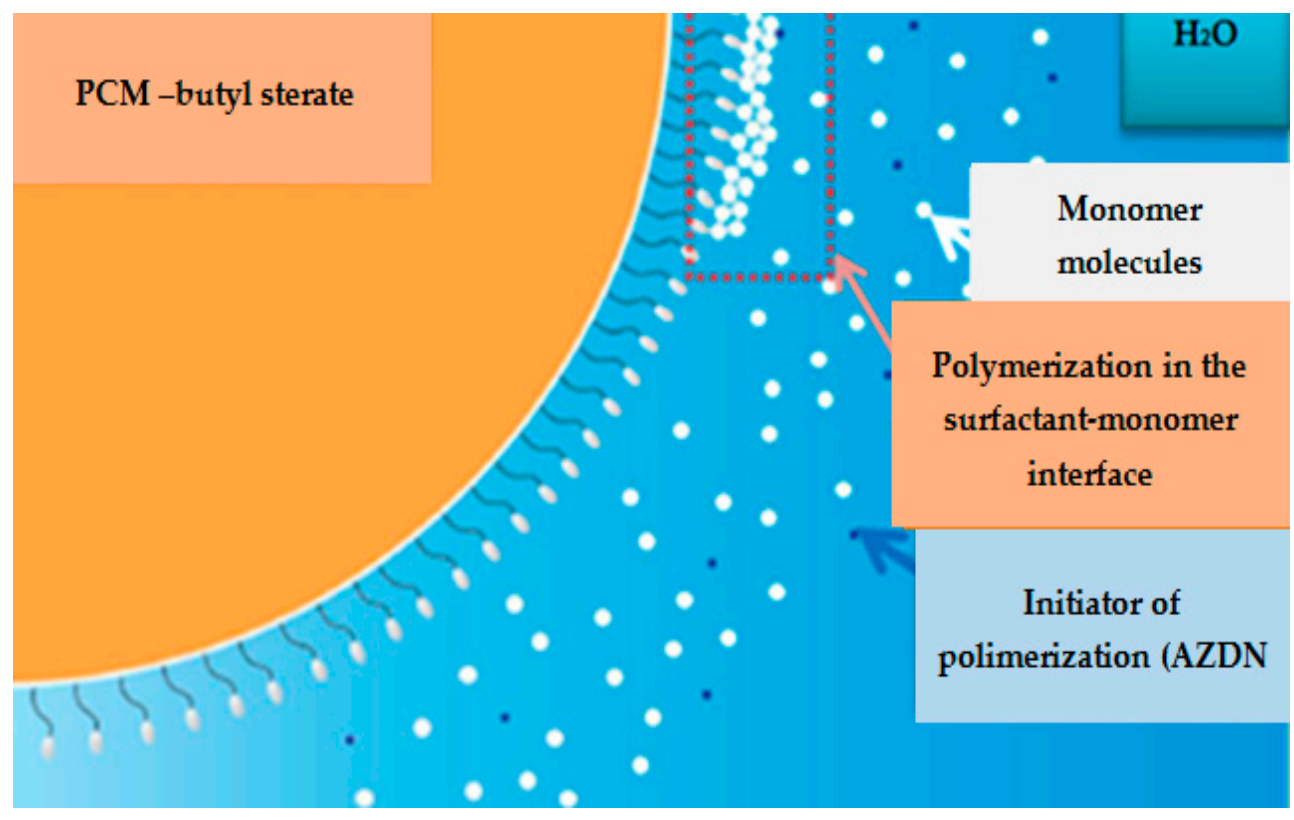

Figure 2. Schematic representation of the complex coacervation polymerization process for a PCM.

Thus, after the butyl stearate-water emulsion was made, the monomer was attached to the surface of the dispersed phase with the surfactant. The azobisisobutyronitrile polymerization initiator (AIBN) was added in the last step of the micro-encapsulation to achieve the PMMA (polymethyl methacrylate) membrane.

Of the plurality of phase change materials, butyl stearate responded best to the requirements for obtaining phase-transforming materials with superior characteristics due to a $19{ }^{\circ} \mathrm{C}$ 
melting/solidification temperature, its availability and low cost, and the large amount of energy stored at phase change.

For butyl stearate to be used in optimal conditions as a phase change material, it was necessary to develop a method of encapsulation to avoid leakage during phase shifts. Thus, the butyl stearate was retained through a complex coacervation microencapsulation process in a membrane of polymethyl methacrylate (PMMA). Choosing PMMA for the encapsulation of butyl stearate was achieved with regard to its physical properties, as seen in Table 1.

Table 1. Physical properties of poly (methyl methacrylate) (PMMA).

\begin{tabular}{ccccccccccc}
\hline Temperature, ${ }^{\circ} \mathrm{C}$ & -200 & -150 & -100 & -50 & 0 & 20 & 50 & 100 & 150 & 200 \\
Calorific capacity $\mathrm{KJ} / \mathrm{Kg} \cdot \mathrm{K}$ & 0.67 & 0.90 & 1.06 & 1.26 & 1.26 & 1.42 & 1.85 & 0.67 & 0.90 & 1.06 \\
Thermal conductivity, $\mathrm{W} / \mathrm{m} \cdot \mathrm{K}$ & 0.16 & 0.18 & 0.19 & 0.19 & 0.19 & 0.19 & 0.20 & 0.19 & 0.18 & 0.16 \\
$\begin{array}{c}\text { Coefficient of linear thermal } \\
\text { expansion, } 1 / \mathrm{K}\end{array}$ & 3.0 & 3.7 & 4.5 & 5.7 & 6.9 & 7.5 & 12.0 & 18.4 & 3.0 & 3.7 \\
\hline
\end{tabular}

Butyl stearate microcapsules were obtained using a polymerization emulsion by the complex coacervation process.

The Butyl stearate, MMA and allyl-MMA used in the process of obtaining the phase-transforming material were purchased from Sigma Aldrich. The azobisisobutyronitrile (AIBN), used as the polymerization initiator, was purchased from ARKEMA Inc. (King of Prussia, PA, USA). The Pluronic PE6200 surfactant was purchased from BASF (Houston, TX, USA). The iron sulphate $\left(\mathrm{FeSO}_{4}-7 \mathrm{H}_{2} \mathrm{O}\right)$, ammonium persulfate, and sodium thiosulphate $\left(\mathrm{NaS}_{2} \mathrm{O}_{7}\right)$ that were used in the various emulsifying steps were purchased from SC Alfa Vega SRL.

For the manufacture of the butyl stearate/PMMA microcapsules, many emulsifying steps were performed using a mini-emulsion apparatus. In order to obtain the first sample of the phase change material, several emulsifying steps were performed, and during the first emulsifying step $120 \mathrm{~mL}$ of water was mixed in a mini-emulsion apparatus for half an hour, deionized, to which was added $30 \mathrm{~g}$ of butyl stearate and $3 \mathrm{~g}$ of Pluronic PE6200 (surfactant).

Since it was necessary for the emulsification process to proceed at a higher temperature than the melting point of butyl stearate, $19{ }^{\circ} \mathrm{C}$, a working temperature of $30{ }^{\circ} \mathrm{C}$ was set. The second emulsification step was made by adding $30 \mathrm{~mL}$ of MMA, $3.5 \mathrm{~g}$ of allyl-MMA, and $1.5 \mathrm{~mL}$ of fresh $\mathrm{FeSO}_{4}-7 \mathrm{H}_{2} \mathrm{O}$ solution, which was obtained by adding $0.3 \mathrm{~g}$ of $\mathrm{FeSO}_{4}-7 \mathrm{H}_{2} \mathrm{O}$ in $200 \mathrm{~mL}$ of water and $0.3 \mathrm{~g}$ of ammonium persulfate respectively. In the third stage of emulsification, the allyl-MMA reticular agent was added. By adding this crosslinking agent, the formation of secondary microcapsules of completely different shapes and sizes was observed, and finally the approximate uniformization of the shapes and sizes of the microcapsules. The addition of the allyl-MMA crosslinker allowed a uniformity of shape and size for the microcapsules, and a substantial increase in the yield of the emulsifying process in this phase, thus reducing the number of emulsifying steps.

During the last step of the emulsification the solution resulting from the third step was mixed at a speed of $2000 \mathrm{rpm}$ for $30 \mathrm{~min}$ and a new solution was obtained corresponding to this step of emulsification. The time required to achieve the final emulsification step was $1.5 \mathrm{~h}$, and $0.30 \mathrm{~g}$ of $\mathrm{Na}_{2} \mathrm{~S}_{2} \mathrm{O}_{7}$ and $1.5 \mathrm{~g}$ of AIBN were added at this stage. After all the emulsification steps, a white precipitate was obtained from the coacervated butyl stearate microcapsules in PMMA membranes. The white precipitate obtained was subjected to a relaxation process for $45 \mathrm{~min}$. Afterwards, the precipitate was mechanically separated from the water, and dried under vacuum for $24 \mathrm{~h}$ at ambient temperature of $20^{\circ} \mathrm{C}$, obtaining the butyl stearate microcapsules encapsulated in PMMA membranes (Figure 3). As a result of these steps, the microcapsules were characterized by high friability, and dimensions between $0.5-3.5 \mathrm{~mm}$ were obtained. 


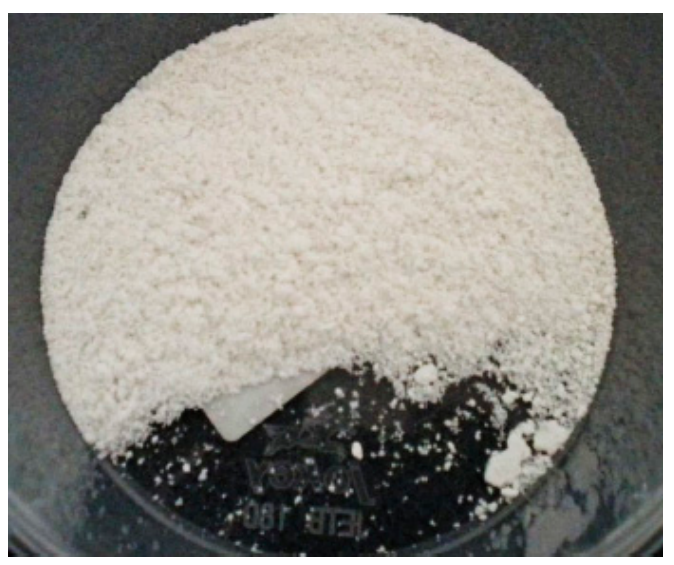

Figure 3. Butyl stearate microcapsules encapsulated in PMMA membranes.

In order to better observe the structure of the achieved microcapsules, they were subjected to an optical microscopic analysis, and the resulting images are presented in Figure 4.

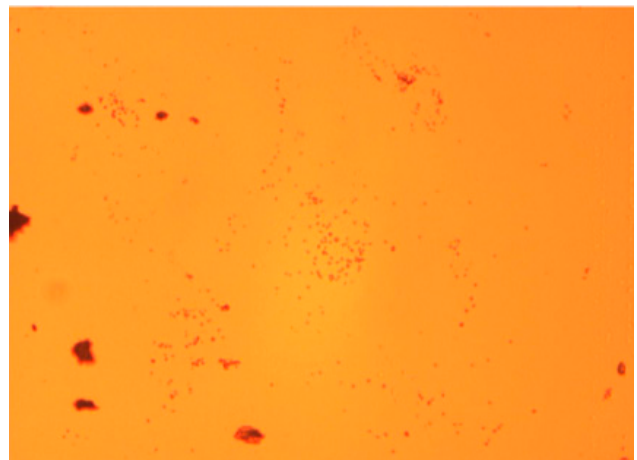

(a)

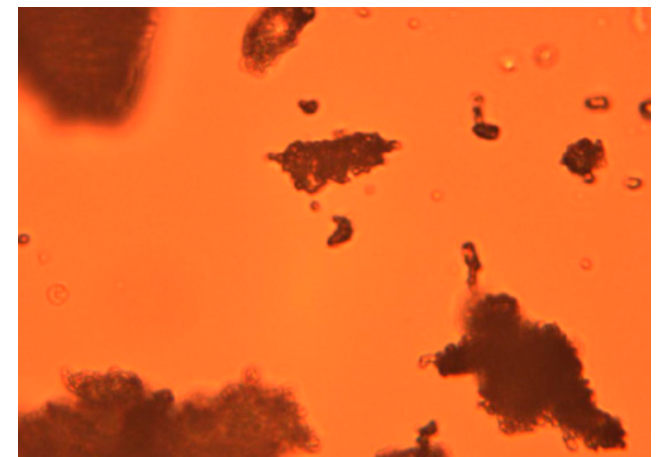

(b)

Figure 4. Images obtained by optical microscopy of microcapsules of butyl stearate-PMMA at different magnifications: (a) $20 \times$; (b) $40 \times$.

From the analysis of the images presented in Figure 4, it was observed that a phase transformation material was obtained that was characterized by non-uniform granulometric distribution and inadequate coacervation due to the non-uniform thickness of the PMMA layer. In view of this, several variants of composite material were further synthesized by modifying certain parameters of the emulsification process. Thus, in order to optimize the process of emulsification to obtain the materials with a performant phase change, a rheological analysis was carried out for different stages of the emulsification. To determine the rheological properties of the materials formed in the various stages of the emulsification of the micro-encapsulation process of the butyl stearate, the rheometer Physica MCR 301 was used, produced by the company Anton Paar. This type of rheometer is very complex and satisfies the most demanding requirements for measuring the rheological and magnetorheological properties of various types of complex fluids, including magnetic fluids, magnetorheological suspensions, magnetofluid composites, polymers, oils, lubricants, and emulsions. This type of rheometer was designed to allow small amounts of samples to be analyzed, between 0.2 and $0.5 \mathrm{~mL}$. In concealed cone-plate and plate-plate systems, either the plate is stationary and the cone rotates or vice versa. The angle between the cone and the plate must be very small, usually with values between $0.1^{\circ}$ and $3^{\circ}$.

The determination of the rheological properties of the intermediate emulsions from the microencapsulation process of the butyl stearate was achieved for the cone-plate geometry and plate-plate. When choosing the geometry of the cone-plate and the plate-plate, the fact that this type of geometry provides uniform speed shear throughout the analyzed sample was taken into account. 
Because the amount of sample that was analyzed was not very large, changes in the sample temperature were considered. In the experiments, different rheological properties of the intermediate emulsions from the micro-encapsulation process of the butyl stearate were established, namely complex viscosity $\eta^{*}$, storage module $G^{\prime}$, loss module $G^{\prime \prime}$. In addition, the determination of the rheological properties was based on the use of dynamic mechanical measurements.

In this case, a constant angular frequency $\omega$ and shear deformation of sinusoidal material y were imposed, depending on the intensity of the initial deformation $\gamma_{0}$ and time $t$. Thus, the dependence or variation of this deformation over time can be expressed by the formula:

$$
\gamma(\mathrm{t})=\gamma_{0} \sin (\omega \mathrm{t})
$$

The determination of the rheological properties of the intermediate emulsions in the micro-encapsulation process of the butyl stearate, namely the storage module $G^{\prime}$, loss module $G^{\prime \prime}$, and the complex viscosity $\eta^{*}$, was made regarding the following calculation relationships:

$$
\begin{gathered}
G^{\prime}=\frac{\tau_{0}}{\gamma_{0}} \cdot \cos \delta \\
G^{\prime \prime}=\frac{\tau_{0}}{\gamma_{0}} \cdot \sin \delta \\
\eta^{*}=\left(G^{\prime}+i G^{\prime \prime}\right) / \omega
\end{gathered}
$$

where: $\gamma_{0}$-amplitude of the initial deformation; $\gamma$-the amplitude of the deformation; $\tau_{0}$-initial shear stress; $\tau_{0}$ — shear stress; $\delta$-phase shift, $\omega$-angular frequency; and $i=\sqrt{-1}$.

Rheological testing was performed on the emulsions obtained in the intermediate steps of the microencapsulation process of butyl stearate. These tests were performed to identify the rheological properties of the emulsions in order to determine their stability over time and to establish the experimental reproducibility of the characteristics of the obtained materials. Therefore, three separate samples (Table 2) were produced from which samples were taken from each of the important stages of

\begin{tabular}{|c|c|c|c|c|}
\hline $\begin{array}{l}\text { Sample } \\
\text { Number }\end{array}$ & $\begin{array}{c}\text { Emulsification } \\
\text { Step }\end{array}$ & Components & Figure & Obs. \\
\hline \multirow{4}{*}{ a } & EM_1a & $\begin{array}{ll}\text { - } & \mathrm{H}_{2} \mathrm{O}[100 \mathrm{~mL}] \\
\text { - } & \text { Surfactant }[2 \mathrm{~g}] \\
\text { - } & \text { Butyl stearate }[25 \mathrm{~g}]\end{array}$ & & \\
\hline & EM_2a & $\begin{array}{ll}\text { - } & \text { EM_1a } \\
\text { - } & \text { MMA }[25 \mathrm{~mL}] \\
\text { - } & \text { FeSO }_{4}[0.0015 \mathrm{~g}] \\
\text { - } & \text { Ammonium persulfate }[0.3 \mathrm{~g}]\end{array}$ & & \\
\hline & EM_3a & - $\mathrm{Na}_{2} \mathrm{~S}_{2} \mathrm{O}_{7}$ & & \\
\hline & EM_4a & • $\quad$ AIBN & $\begin{array}{c}9 \\
10\end{array}$ & $\begin{array}{l}\text { after } 24 \mathrm{~h} \text { of } \\
\text { manufacture }\end{array}$ \\
\hline \multirow{4}{*}{$\mathrm{b}$} & EM_1b & $\begin{array}{ll}\text { - } & \mathrm{H}_{2} \mathrm{O}[100 \mathrm{~mL}] \\
\text { - } & \text { Surfactant }[2 \mathrm{~g}] \\
\text { Butyl stearate }[25 \mathrm{~g}]\end{array}$ & $\begin{array}{l}5 \\
7 \\
8\end{array}$ & $\begin{array}{l}\text { rigorous stirring } \\
\text { after } 10 \text { min of } \\
\text { relaxation }\end{array}$ \\
\hline & EM_2b & $\begin{array}{ll}\text { - } & \text { EM_1b } \\
\text { - } & \text { MMA }[25 \mathrm{~mL}] \\
\text { - } & \mathrm{FeSO}_{4}[0.0015 \mathrm{~g}] \\
\text { - } & \text { Ammonium persulfate }[0.3 \mathrm{~g}]\end{array}$ & & \\
\hline & EM_3b & - $\mathrm{Na}_{2} \mathrm{~S}_{2} \mathrm{O}_{7}$ & & \\
\hline & EM_4b & - $\quad$ AIBN & 11 & \\
\hline
\end{tabular}
the emulsification process, and rheological testing was performed with two different angular speeds, namely $\omega=1 \mathrm{rad} / \mathrm{s}$ and $\omega=10 \mathrm{rad} / \mathrm{s}$.

Table 2. Sample emulsification technologies. 
Table 2. Cont

\begin{tabular}{|c|c|c|c|c|}
\hline $\begin{array}{l}\text { Sample } \\
\text { Number }\end{array}$ & $\begin{array}{l}\text { Emulsification } \\
\text { Step }\end{array}$ & Components & Figure & Obs. \\
\hline \multirow{6}{*}{$c$} & EM_1c & $\begin{array}{ll}\text { - } & \mathrm{H}_{2} \mathrm{O}[100 \mathrm{~mL}] \\
\text { - } & \text { Surfactant }[2 \mathrm{~g}] \\
\text { - } & \text { Butyl stearate }[25 \mathrm{~g}]\end{array}$ & 6 & \\
\hline & EM_2c & $\begin{array}{ll}- & \text { EM_1c } \\
- & \text { MMA }[25 \mathrm{~mL}]\end{array}$ & 14 & $\begin{array}{l}\text { after } 24 \mathrm{~h} \text { of } \\
\text { manufacture }\end{array}$ \\
\hline & EM_3c & - $\mathrm{FeSO}_{4}[0.0015 \mathrm{~g}]$ & & \\
\hline & \multirow[t]{2}{*}{ EM_4c } & \multirow{2}{*}{ - Ammonium persulfate $[0.3 \mathrm{~g}]$} & 12 & \\
\hline & & & 13 & $\begin{array}{l}\text { after } 2 \text { min of } \\
\text { relaxation }\end{array}$ \\
\hline & EM_5c & $\mathrm{Na}_{2} \mathrm{~S}_{2} \mathrm{O}_{7}$ & 15 & $\begin{array}{l}\text { after } 24 \mathrm{~h} \text { of } \\
\text { manufacture }\end{array}$ \\
\hline
\end{tabular}

\section{Results and Discussion}

The rheological properties were tested for the three samples made using different emulsification technologies, as seen in Table 2. Three samples were tested to determine the stability of the emulsions, the reproducibility of the obtained results and the optimization of the emulsifying steps in order to obtain PCMs with the best performance.

After rheological testing of Sample B for the EM1_b step 1 emulsifier, with an angular speed $\omega=1 \mathrm{rad} / \mathrm{s}$, see Figure 5, it was observed that the sample was almost devoid of elasticity because the storage module was much smaller than the loss module, thus it was concluded that after this step of emulsification the viscosity of the obtained substance was larger and had values between $0.8 \mathrm{~Pa}$ and $3 \mathrm{~Pa}$, which are much higher than that of water.

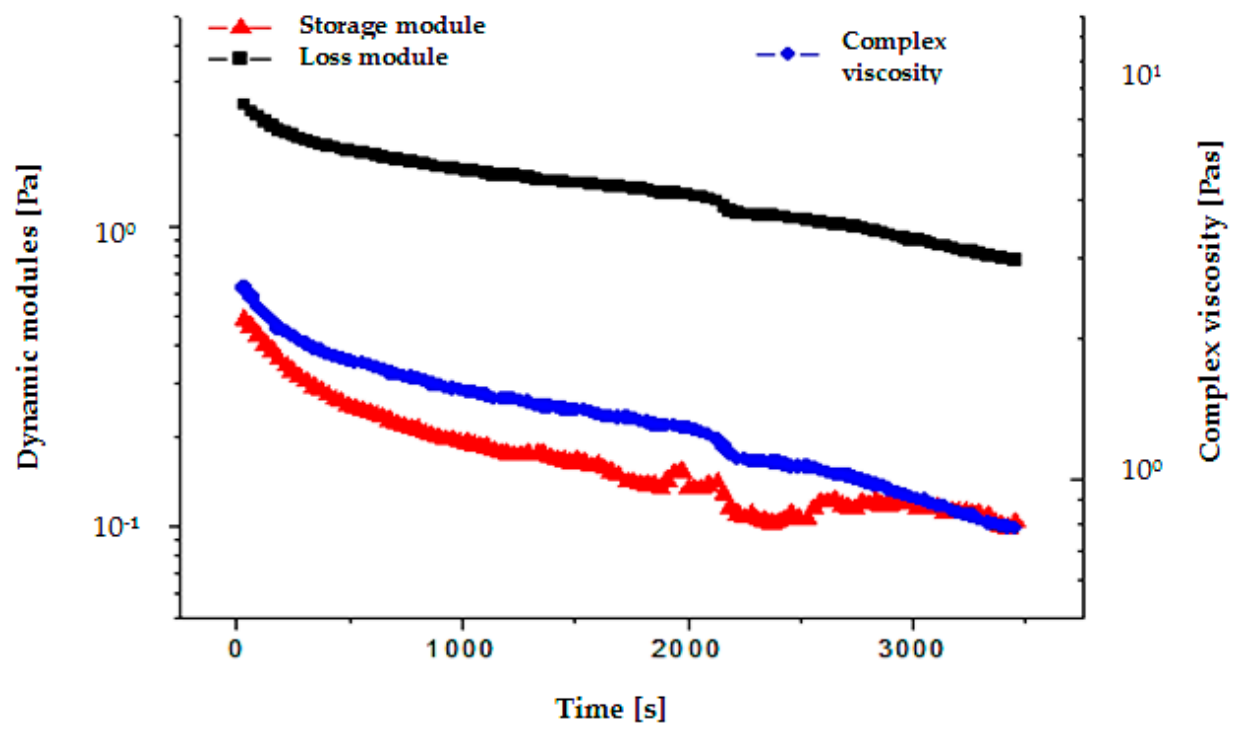

Figure 5. Storage module, loss module and complex viscosity for EM_1b.

From the rheological test of Sample C for emulsifying step 1, see Figure 6, it was found that the sample was completely devoid of elasticity, and the viscosity of the complex had decreased relative to the previous sample shown in Figure 6. 


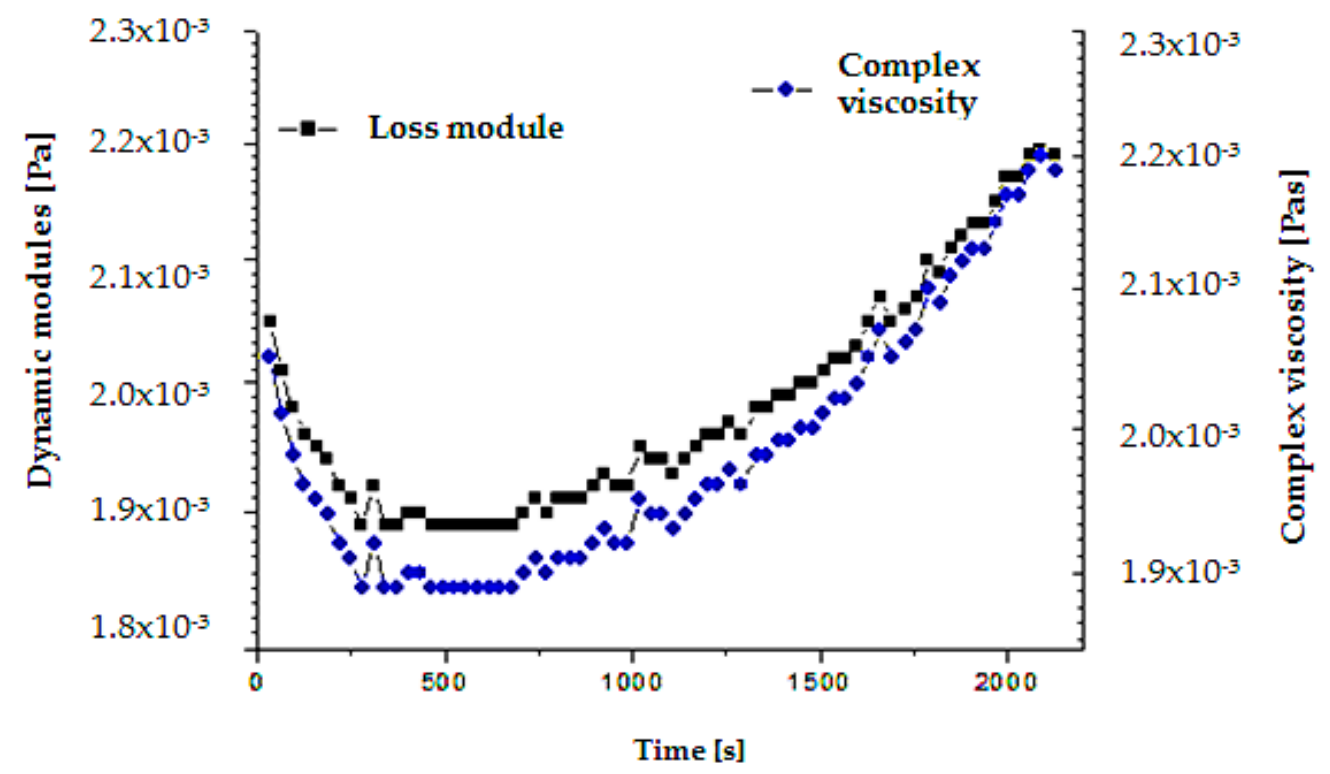

Figure 6. Loss module and complex viscosity for EM_1c after light shaking.

The rheological analysis of the sample EM1b after rigorous stirring, see Figures 7 and 8, demonstrated that the storage module increased from the previous sample (Figure 6) and was approximately constant (equal to $0.012 \mathrm{~Pa}$ ), and the complex viscosity decreased and was approximately ten times larger than that of water. This demonstrates that an appropriate emulsification occurred when the emulsifying process was accompanied by rigorous stirring.

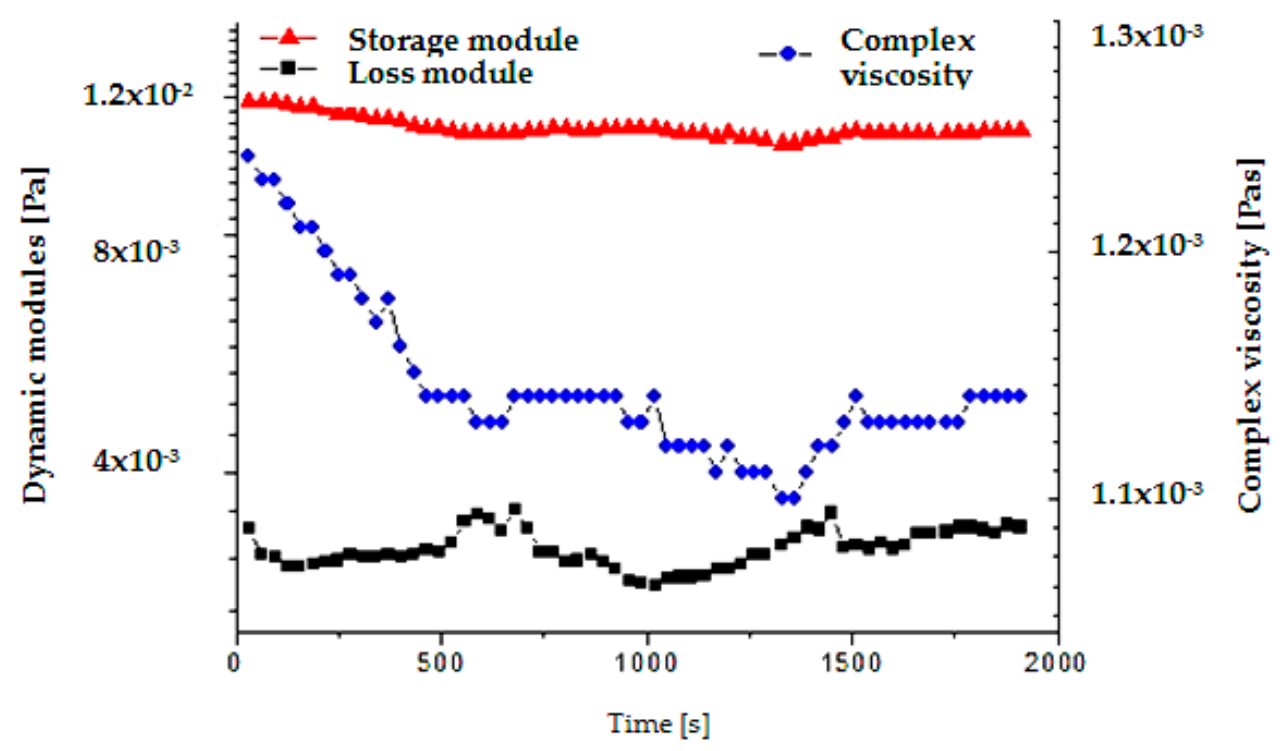

Figure 7. Storage module, loss module and complex viscosity for EM_1b after rigorous stirring. 


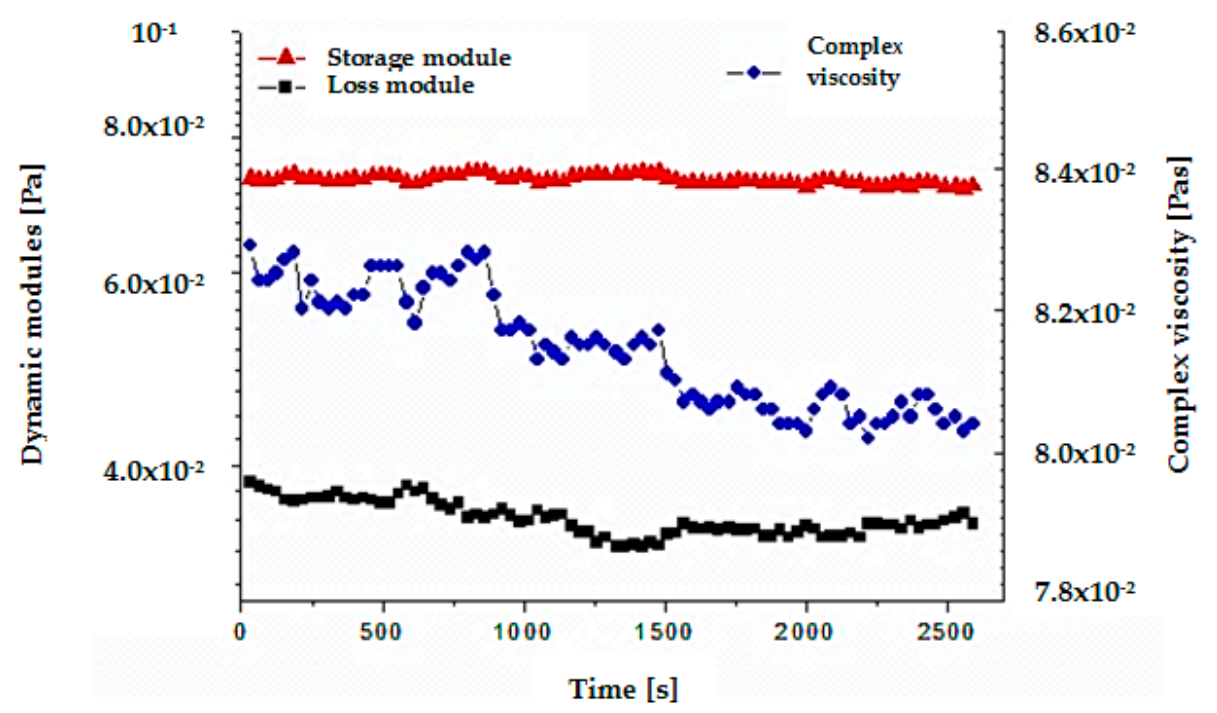

Figure 8. Storage module, loss module and complex viscosity for EM $1 \mathrm{~b}$ after a relaxation period of $10 \mathrm{~min}$.

An important factor that can influence the properties of the material may be the period of relaxation between the various stages of emulsification. Thus, EM_1b, was subjected to a relaxation process of $10 \mathrm{~min}$ storage module, increased from the previous sample by approximately six times, from $0.012 \mathrm{~Pa}$ to $0.08 \mathrm{~Pa}$. The complex viscosity also increased. This demonstrates that it was necessary to optimize the relaxation period between the various stages of emulsification. In the case of sample EM_4a, from the rheological properties, see Figure 9, it was observed that up to a time $t=250 \mathrm{~s}$, the viscous part of the material was preponderant compared to the elastic part of the material, and after $250 \mathrm{~s}$, the ratio changed and the loss module was higher than the elastic module. Since this step was the last step in the encapsulation process it can be concluded that the point of change of the ratio between the two modules represents the beginning of the polymerization reaction of the MMA.

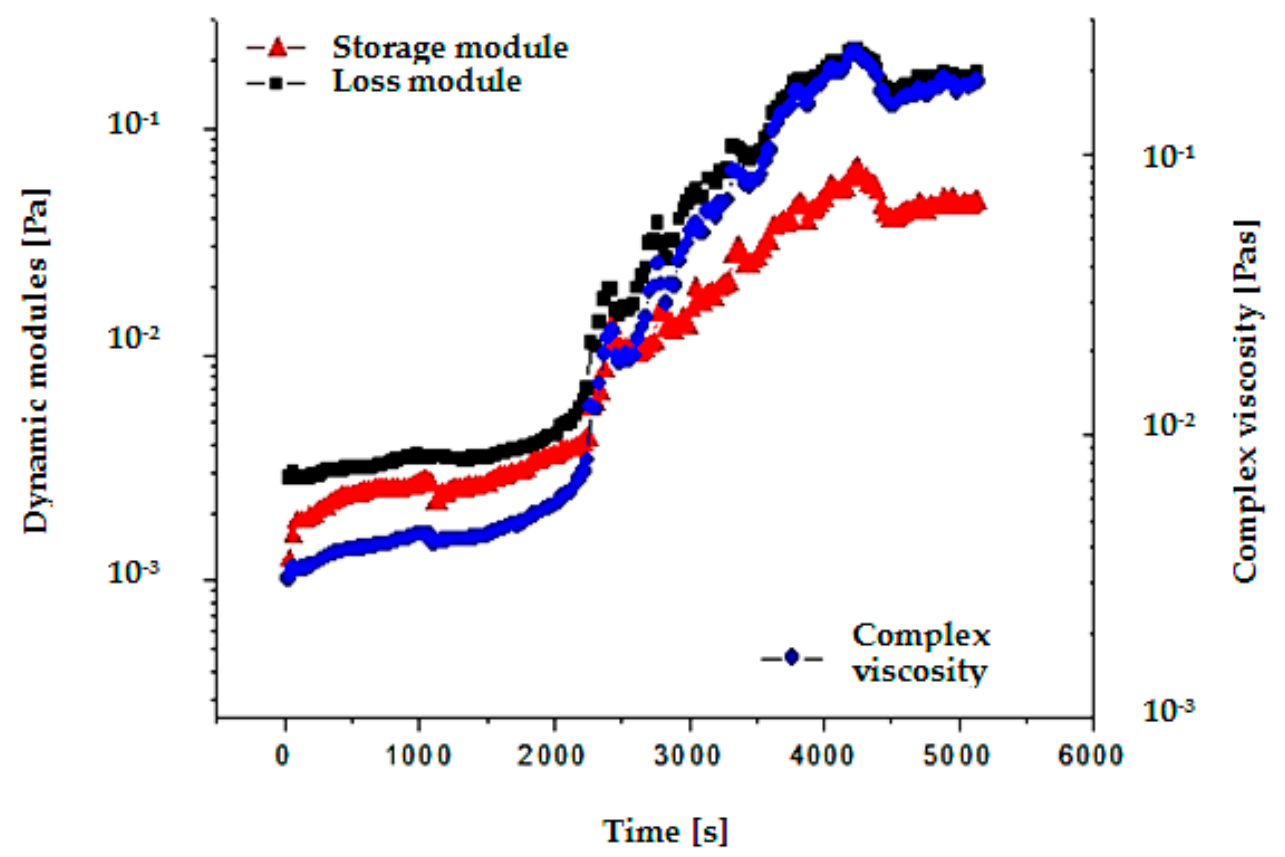

Figure 9. Storage module, loss module and complex viscosity for EM_4a.

From the analysis of the rheological properties of sample EM_4a, measured at $24 \mathrm{~h}$ after production, see Figure 10, it was observed that for the same emulsion, the storage module was 
greater than the loss module over the duration of the measurements. This change was due to the $24 \mathrm{~h}$ of rest and therefore the completion of the polymerization process. The complex viscosity had a much smaller variation over the $3500 \mathrm{~s}$ (measurement duration) than the previous sample.

Regarding the storage module evolution, loss module and complex viscosity for EM_4b, see Figure 11, an important increase in the storage module and loss module and complex viscosity was observed approximately one hour from the start of measurement. This increase can be explained by the completion of the polymerization process, which happens during the emulsion process.

The evolution graph of the storage module, loss module and of the complex viscosity for sample EM_4c, see Figure 12, shows a change in curvature due to the mixing process to which the sample was subjected.

It was also observed that the loss module was greater than the storage module. Under these conditions it is necessary to optimize the process of mixing from the emulsification steps. The relaxation of the sample EM_3c made the complex viscosity decrease from the previous sample, but the loss module still remained higher than the storage module. In the EM-4c emulsion, see Figures 12-14, it was observed that the complex viscosity decreased with the increase in $\omega$, and the sample was no longer elastic. The same observation can be made for the emulsion EM_5c in Figure 15.

During the rheological testing of the butyl stearate, it was observed that the sample had a complex viscosity nine times higher that of water, the loss module was ten times greater than the elastic module, and all three sizes were approximately constant during the measurement, Figure 16.

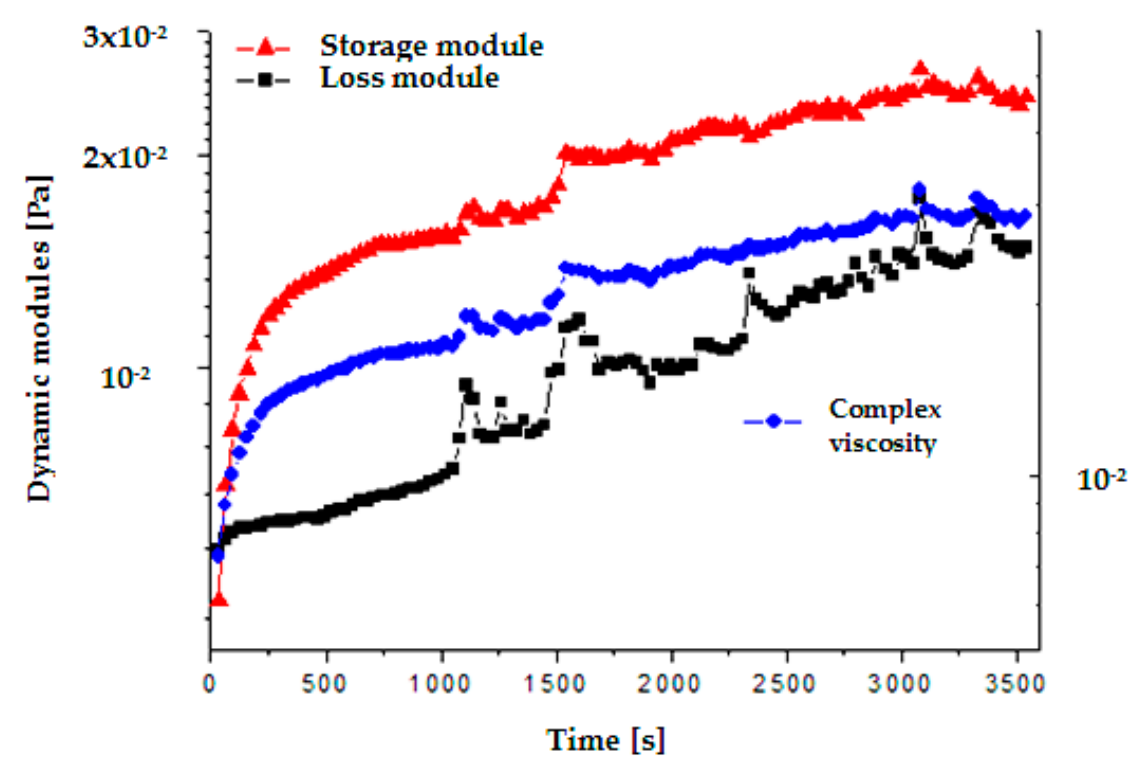

Figure 10. Storage module, loss module and complex viscosity for EM_4a, measured $24 \mathrm{~h}$ from manufacturing. 


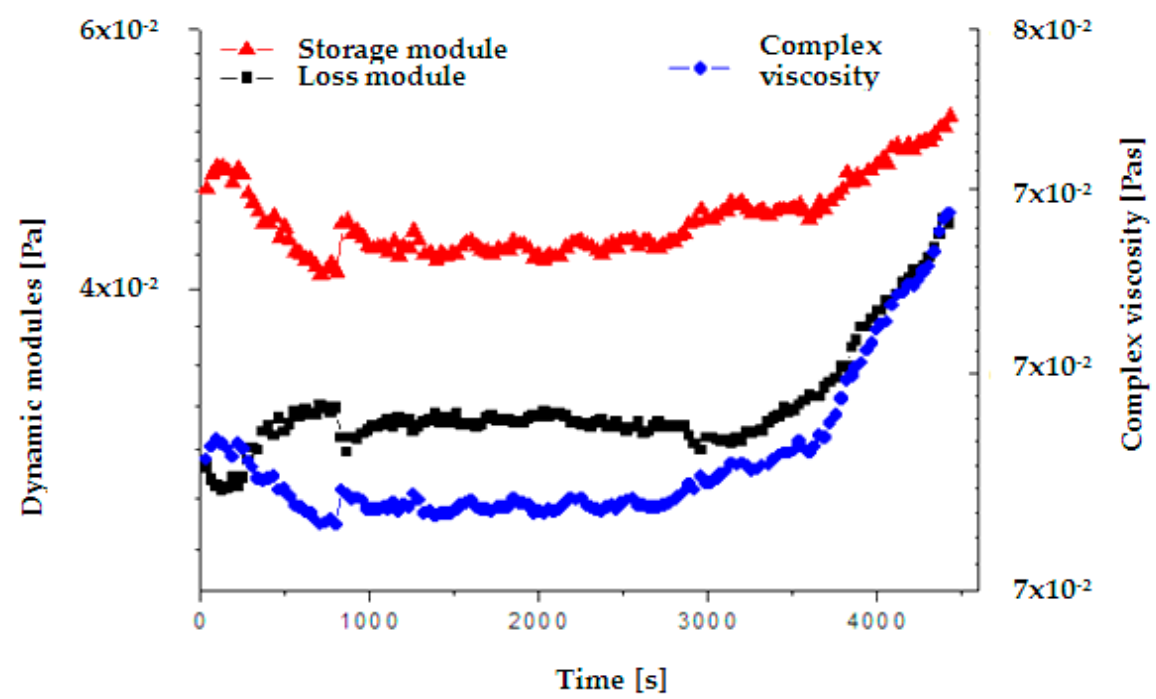

Figure 11. Storage module, loss module and complex viscosity for EM_4b.

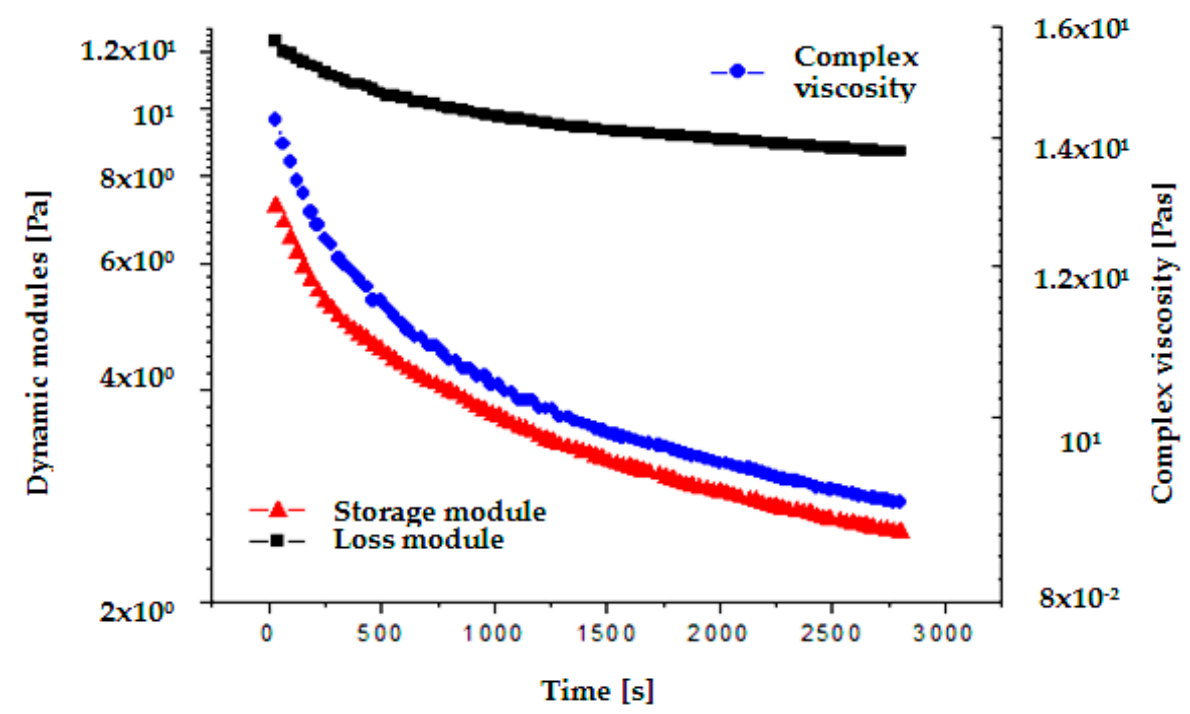

Figure 12. Storage module, loss module and complex viscosity for EM_4c.

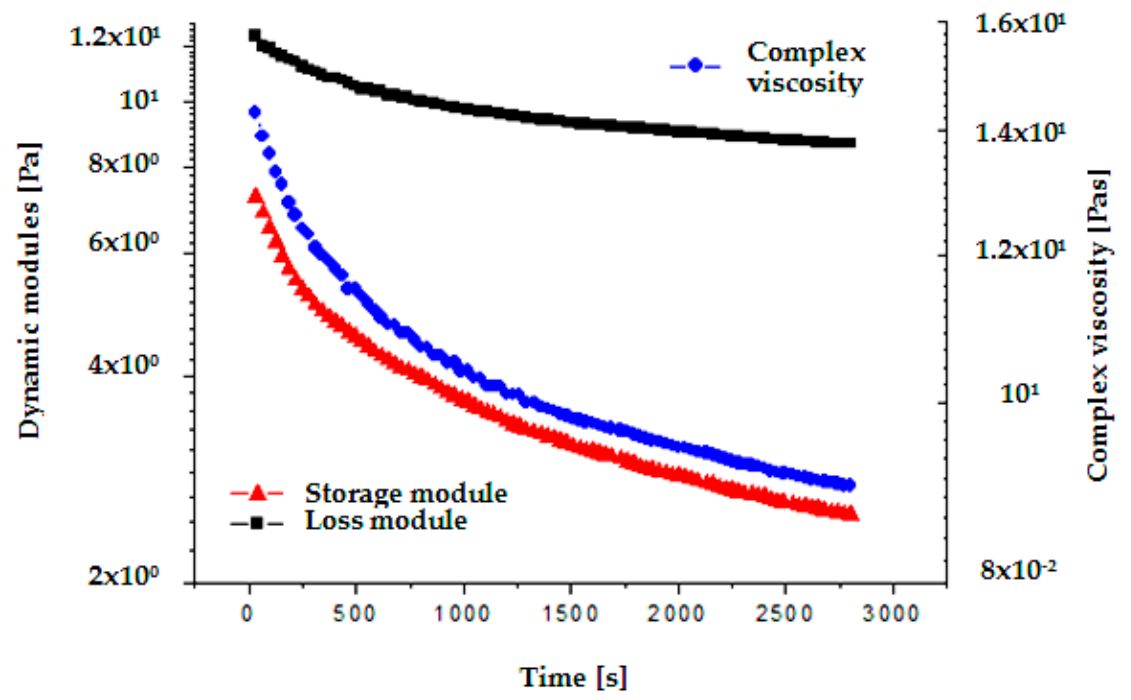

Figure 13. Storage module, loss module and complex viscosity for EM_4c, after a 2 min relaxation. 
For a comparative analysis of the influence of angular speed on the rheological properties, the following tests were carried out at the angular speed $\omega=10$ rad.

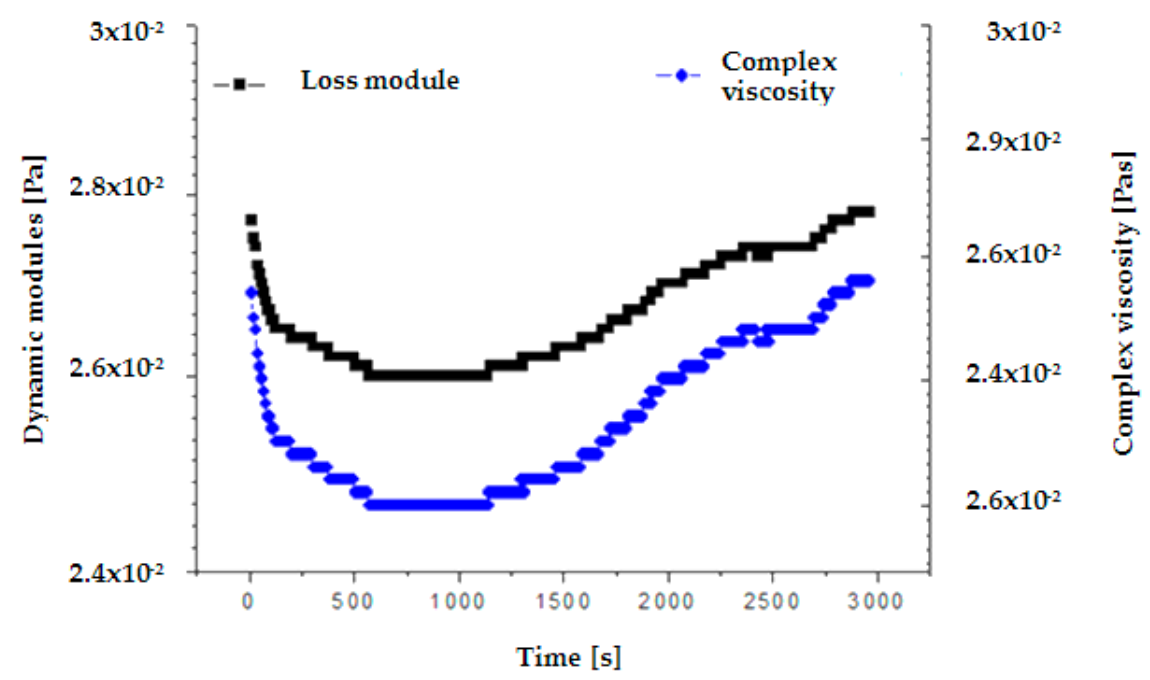

Figure 14. Loss module and complex viscosity for EM_2c after $24 \mathrm{~h}$ from manufacturing.

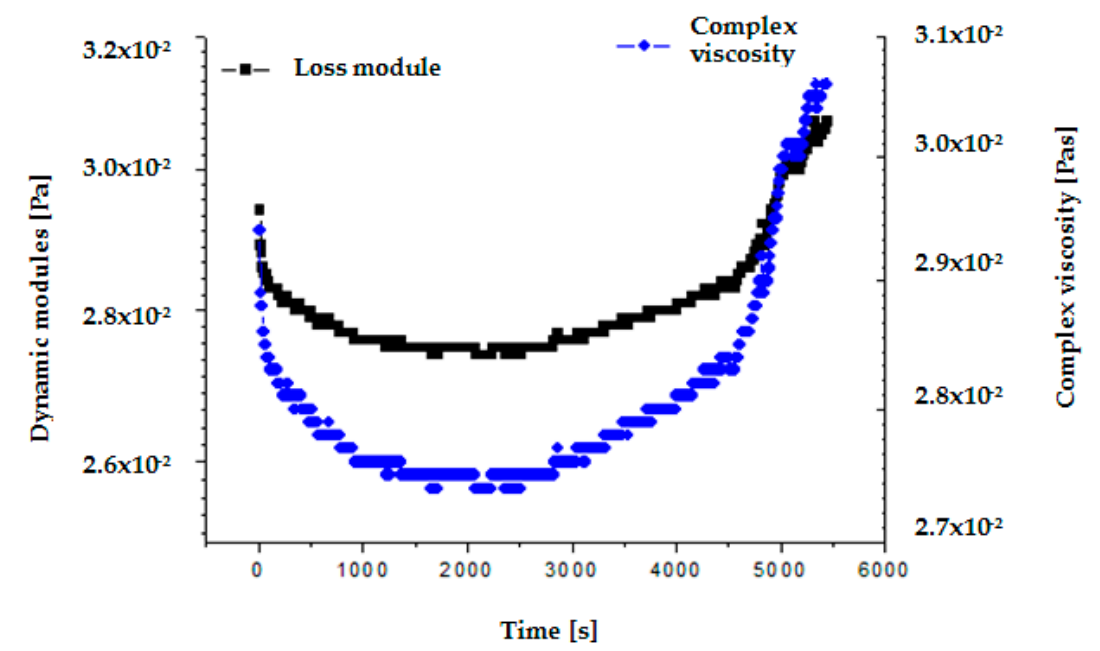

Figure 15. Loss module and complex viscosity for EM_5c measured at $24 \mathrm{~h}$ after manufacturing.

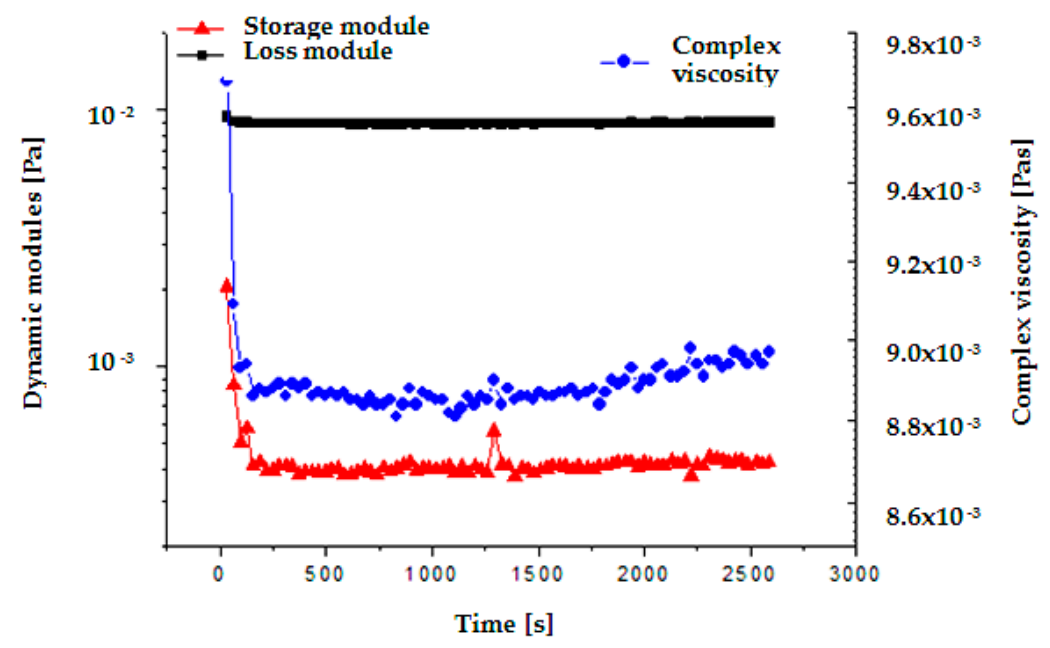

Figure 16. Storage module, loss module and complex viscosity for butyl stearate. 
The rheological properties were analyzed for different stages of emulsification and different conditions were considered, namely light stirring, rigorous stirring, relaxation periods of $2 \mathrm{~min}, 10 \mathrm{~min}$, and $24 \mathrm{~h}$ after manufacturing. Thus, it was established that although the emulsifying conditions were the same for both Sample B and Sample C, the rheological properties determined were different. This meant that rigorous stirring resulted in our obtaining rheological properties corresponding to the formation of a PMMA membrane with a uniform thickness over the butyl stearate particles. It was also established that some relaxation time is required after each emulsifying step to complete the corresponding polymerization process. The rheological analysis was performed for different relaxation periods of $2 \mathrm{~min}$ and $10 \mathrm{~min}$. We concluded that the longer relaxation period led to obtaining coacervated PCMs that can be successfully used in the manufacturing process of various building materials while avoiding the leakage of phase change materials and ensuring the best insulation of buildings.

\section{Conclusions}

Following the rheological testing of emulsions obtained in the intermediary steps of a microencapsulation process using the complex coacervation of butyl stearate in polymethyl methacrylate membranes, the following conclusions were made:

- Through the coacervation process, microcapsules can be made to incorporate different types of materials to supplement secondary functions and/or to compensate for these functions under different environmental conditions with the help of the capsules.

- When the MMA polymerization reaction is triggered, the loss module of the sample becomes greater than the storage module, substantially influencing the process of forming the MMA layer over the butyl stearate particles.

- It is advisable that covering particles with MMA be accomplished within $250 \mathrm{~s}$, because after this time MMA polymerization begins, which increases the loss module, and prevents the uniform distribution of MMA on the surface of the butyl-stearate particles.

- An appropriate emulsification is carried out under conditions where the emulsifying process has been accompanied by rigorous stirring.

- When rheological testing was performed $24 \mathrm{~h}$ after the last emulsification step, it was observed that the storage module was greater than the loss module over the duration of the measurements. This can be explained by the finalization of the polymerization process of the MMA.

- The rheological test using butyl stearate showed that it had a complex viscosity nine times higher than that of water, with the loss module being ten times higher than the elastic module.

- The optimization of the technological parameters corresponding to the emulsifying steps (mixing time, polymerization time, manufacturing temperature, mixing speed) allowed us to obtain coacervated PCMs that can be successfully used in the manufacturing processes of various building materials, avoiding the leakage of phase change materials and ensuring the best thermal insulation of buildings.

Research has focused on improving emulsification technologies for the manufacturing of energy efficient PCMs. Because the results obtained showed high loss modules, and this type of material can be used successfully for the sound insulation of buildings, in the future we will address the issue of using such materials as building materials that allow good sound insulation.

Author Contributions: D.D. and V.B.-conceptualization and design experiment; T.D., G.E. and N.-E.P. performed the experiments; D.D., V.B., T.D., G.E. and N.-E.P.- analyzed the data; D.D. writing-original draft preparation; D.D., V.B., T.D., G.E. and N.-E.P. have read, corrected and approved the manuscript.

Funding: This research received no external funding.

Conflicts of Interest: The authors declare no conflict of interest. 


\section{References}

1. Bland, A.; Khzouz, M.; Statheros, T.; Gkanas, E.I. PCMs for Residential Building Applications: A Short Review Focused on Disadvantages and Proposals for Future Development. Buildings 2017, 7, 78. [CrossRef]

2. Tyagi, V.V.; Buddhi, D. PCM thermal storage in buildings: A state of art. Renew. Sustain. Energy Rev. 2007, 11, 1146-1166. [CrossRef]

3. Bendic, V.; Dobrotă, D. Theoretical and Experimental Contributions on the Use of Smart Composite Materials in the Construction of Civil Buildings with Low Energy Consumption. Energies 2018, 11, 2310. [CrossRef]

4. Zhou, D.; Zhao, C.Y.; Tian, Y. Review on thermal energy storage with phase change materials (PCMs) in building applications. Appl. Energy 2012, 92, 593-605. [CrossRef]

5. Branko, Š. Smart Crack Control in Concrete through Use of Phase Change Materials (PCMs): A Review. Materials 2018, 11, 654 .

6. Johan, H.; Chris, B.; Viktoria, M. Combining thermal energy storage with buildings-A review. Renew. Sustain. Energy Rev. 2015, 42, 1305-1325.

7. Gracia, A.; Cabeza, L. Phase change materials and thermal energy storage for buildings. Energy Build. 2015, 103, 414-419. [CrossRef]

8. Zhang, Y.; Zhou, G.; Lin, K.; Zhang, Q.; Di, H. Application of latent thermal energy storage in buildings: State-of-the-art and outlook. Build. Environ. 2007, 42, 2197-2209. [CrossRef]

9. Chen, F. Leakage Control and Characterization of Form Stable Phase Change Materials: Polymer (Matrix)/Polymer (PCM) Binary Blends and Natural Fiber/Polymer(Matrix)/Polymer (PCM) Ternary Composites; Washington State University: Pullman, WA, USA, 2013; Volume 131.

10. Chen, F.; Wolcott, M.P. Miscibility studies of paraffin/polyethylene blends as form-stable phase change materials. Eur. Polym. J. 2014, 52, 44-52. [CrossRef]

11. Chen, F.; Wolcott, M.P. Polyethylene/paraffin binary composites for phase change material energy storage in building: A morphology, thermal properties, and paraffin leakage study. Sol. Energy Mater. Sol. Cells 2015, 137, 79-85. [CrossRef]

12. Rufuss, D.D.W.; Suganthi, L.; Iniyan, S.; Davies, P.A. Effects of nanoparticle-enhanced phase change material (NPCM) on solar still productivity. J. Clean. Prod. 2018, 192, 9-29. [CrossRef]

13. Chung, M.H.; Park, J.C. An Experimental Study on the Thermal Performance of Phase-Change Material and Wood-Plastic Composites for Building Roofs. Energies 2017, 10, 195. [CrossRef]

14. Yin, Q.; Zhu, Z.; Li, W.; Guo, M.; Wang, Y.; Wang, J.; Zhang, X. Fabrication and performance of composite microencapsulated phase change materials with palmitic acid ethyl ester as core. Polymers 2018, 10, 726. [CrossRef]

15. Ye, R.; Fang, X.; Zhang, Z.; Gao, X. Preparation, Mechanical and Thermal Properties of Cement Board with Expanded Perlite Based Composite Phase Change Material for Improving Buildings Thermal Behavior. Materials 2015, 8, 7702-7713. [CrossRef] [PubMed]

16. Konuklu, Y.; Ostry, M.; Paksoy, O.H.; Charvat, P. Review on using microencapsulated phase change materials (PCM) in building applications. Energy Build. 2015, 106, 134-155. [CrossRef]

17. Vyas, G.S.; Jha, K.N. Benchmarking green building attributes to achieve cost effectiveness using a data envelopment analysis. Sustain. Cities Soc. 2017, 28, 127-134. [CrossRef]

18. Rwei, S.P.; Tuan, H.N.; Chiang, W.Y.; Way, T.F. Synthesis and characterization of pH and thermo dual-responsive hydrogels with a semi-IPN structure based on $\mathrm{N}$-Isopropylacrylamide and Itaconamic Acid. Materials 2018, 11, 696. [CrossRef]

19. Aguilar, M.R.; Roman, J.S. Smart Polymers and Their Applications; Elsevier: Amsterdam, The Netherlands, 2014.

20. Kumar, A.; Srivastava, A.; Galaev, I.Y.; Mattiasson, B. Smart polymers: Physical forms and bioengineering applications. Prog. Polym. Sci. 2007, 32, 1203-1237. [CrossRef]

21. Alam, T.E. Experimental Investigation of Encapsulated Phase Change Materials for Thermal Energy Storage. Ph.D. Thesis, University of South Florida, Tampa, FL, USA, 2015.

22. Adewale, P.; Christopher, L.P. Thermal and Rheological Properties of Crude Tall Oil for Use in Biodiesel Production. Processes 2017, 5, 59. [CrossRef]

23. Guarino, F.; Longo, S.; Ceilura, M.; Mistreta, M.; La Rocca, V. Phase Change Materials Applications to Optimize Cooling Performance of Buildings in the Mediterranean Area: A Parametric Analysis. Energy Procedia 2015, 78, 1708-1713. [CrossRef] 
24. Memon, S.A.; Liao, W.; Yang, S.; Cui, H.; Shah, S.F.A. Development of composite PCMs by incorporation of paraffin into various building materials. Materials 2015, 8, 499-518. [CrossRef] [PubMed]

25. Yang, H.; Memon, S.A.; Bao, X.; Cui, H.; Li, D. Design and preparation of carbon based composite phase change material for energy piles. Materials 2017, 10, 391. [CrossRef] [PubMed]

26. O'Mahony, C.; Ul Haq, E.; Sillien, C.; Syed, A.M. Tofail, Rheological Issues in Carbon-Based Inks for Additive Manufacturing. Micromachines 2019, 10, 99. [CrossRef]

27. Norvell, C.; Sailor, D.J.; Dusicka, P. The effect of microencapsulated phase-change material on the compressive strength of structural concrete. J. Green Build. 2013, 8, 116-124. [CrossRef]

(C) 2019 by the authors. Licensee MDPI, Basel, Switzerland. This article is an open access article distributed under the terms and conditions of the Creative Commons Attribution (CC BY) license (http:/ / creativecommons.org/licenses/by/4.0/). 